\section{Alinhamento estratégico entre Tecnologia da Informação (TI) e o Negócio (NE): estudo de caso no segmento de distribuição de peças de reposição de uma empresa de máquinas agrícolas*}

\author{
Strategic Alignment between Information \\ Technology (IT) and Business (NE): case study on \\ an agricultural machinery spare parts distribution \\ segment company
}

Elenilton Rudiger Johann' Adriane Regina Garippe Johann ${ }^{2}$ Elisângela Rudiger Johann ${ }^{3}$

* Recebido em: $23 / 06 / 2014$

Aprovado em: 27/10/2014

1 Doutor em Administração Estratégica pela PUC-PR (2014), Mestre em Administração Estratégica pela PUC-PR (2009), Pós Graduado em Administração Financeira pela Fundação Getúlio Vargas - RJ (2002), Graduado em Ciências Contábeis pela Universidade de Santa Cruz do Sul (1999).

2 Mestranda em Agronegócio pela Universidade Federal de Goiás - UFG, Pós graduada em Logística Empresarial pela PUC-PR (2010), Graduada em Administração de Empresas pela Fundação de Estudos Sociais do Paraná - FESP-PR (1999).

3 Mestranda em Desenvolvimento Regional pela Universidade de Santa Cruz do Sul, Graduada em Comunicação Social - Radialismo - Produção em Mídia Audiovisual pela Universidade de Santa Cruz do Sul (2010).

\section{Resumo}

O presente estudo consiste em identificar, caracterizar e avaliar, por meio de um estudo de caso, se as estratégias de tecnologia da informação (TI) estão alinhadas às estratégias do negócio junto ao segmento de distribuição de peças de reposição da empresa Alfa, procurando contribuir efetivamente em relação à melhoria para este alinhamento estratégico. O alinhamento estratégico integrado entre as áreas de negócio e de TI tem se tornado uma exigência nas organizações que visualizam manterem-se e crescerem sustentavelmente em um ambiente competitivo. O levantamento de percepções dos executivos de TI e do negócio, a respeito do alinhamento estratégico da TI, teve como principal ferramenta um questionário estruturado aplicado a oito colaboradores-chave, quatro da TI e quatro do negócio junto ao segmento de peças de reposição. Esse questionário foi composto de 47 questões, em escala do tipo Likert de 5 graus, de modo a obter dos colaboradores sua percepção sobre variáveis que traduzissem o grau de alinhamento estratégico. De forma complementar, foram efetuadas entrevistas não estruturadas. Os principais resultados encontrados mostram que o contexto organizacional na empresa Alfa indica condições desfavoráveis à promoção de alinhamento estratégico de TI, existindo, dessa forma, um grau de alinhamento baixo. Como contribuição adicional, recomenda-se sensibilizar os gerentes da organização na importância em auxiliar a TI na implantação de suas ações, bem como implantação de indicadores de desempenho, pois seguramente isso trará uma melhora efetiva em seus processos internos e externos, bem como uma real vantagem competitiva.

Palavras-chave: Alinhamento estratégico. Tecnologia da informação. Negócio. Vantagem competitiva.

\begin{abstract}
This study consist to identify, characterize and evaluate through a case study if the information technology (IT) strategies are aligned with business strategies in the spare parts distribution segment of Alpha Company, seeking to contribute effectively the improvement for this strategic alignment. The integrated strategic alignment between the business areas and IT has become a requirement in organizations that wants to grow sustainably in a competitive environment. The survey of perceptions of IT executives and business regarding IT strategic alignment, had as its main tool a structured questionnaire applied in eight key employees, four in IT and four in the business segment of spare parts. This questionnaire consisted of 47 questions in Likert scale of 5 degrees, in order to obtain the respondent's perception of its variables to translate the degree of strategic alignment. Complementarily, unstructured interviews were conducted. The main results show that the organizational context at Alfa Company indicates unfavorable conditions for the promotion of IT strategic alignment, showing a low degree alignment. As an additional contribution, it is recommended to sensitize managers to the importance to assist IT in its implementations and actions, as well as implementation of performance indicators, as surely this will bring an improvement in their internal and external processes, as well as a real competitive advantage.
\end{abstract}

Keywords: Strategic Alignment. Information Technology. Business. Competitive Advantage. 


\section{Introdução}

Alinhar e integrar os recursos da tecnologia da informação (TI) ao negócio da empresa é assunto de destaque e um problema estratégico para as organizações. $\mathrm{O}$ alinhamento estratégico integrado entre as áreas de negócio e de TI tem se tornado uma exigência nas organizações que visualizam manterem-se e crescerem sustentavelmente em um ambiente competitivo. A pesquisa desenvolvida se enquadra na área de Sistemas de Informação, uma vez que pressupõe analisar Sistemas de Informação como ferramenta de suporte e de alinhamento estratégico ao negócio.

Um mercado globalizado, de constantes mudanças econômicas e culturais, bem como consumidores cada vez mais exigentes, leva as empresas a buscarem sua sobrevivência por meio de maior competitividade no intuito de atingir os seus objetivos. De acordo com essa realidade, os gestores de TI e de Negócio (NE) vêm considerando o alinhamento estratégico de TI e de Negócio como um dos principais norteadores na identificação de novas oportunidades e vantagens competitivas perante seus competidores. No entanto, apesar do conhecimento do impacto positivo na organização, ainda existem elementos inibidores desse alinhamento, tais como problemas de comunicação, perda de recursos ou de comprometimento (LEDERER; SETHI, 1996; REICH; BENBASAT, 1996).

Dos mais diversos conceitos existentes, pode-se considerar que o alinhamento estratégico entre TI e negócio ocorre quando o conjunto de estratégias de sistemas de informação (SI) é derivado do conjunto estratégico organizacional (KING, 1978). Este trabalho tem como objetivo avaliar se o planejamento estratégico de TI está alinhado ao planejamento estratégico do Negócio, pautando-se numa empresa do segmento de Distribuição de Peças de Reposição para Máquinas Agrícolas. Acredita-se poder contribuir para que a companhia e seus colaboradores saibam efetivamente quais os elementos e variáveis de alinhamento estratégico devem ser focados para com o uso de TI buscar melhoria em seus processos internos e externos, bem como vantagem competitiva.

\section{Fundamentação teórica}

\subsection{Sistema de Informação e Tecnologia da Informação}

É importante destacar uma ambiguidade conceitual apresentada para o termo TI e SI (Sistema da Infor- mação). Para alguns autores, TI é considerada apenas uma infraestrutura de suporte para os SI, porém, para outros autores, TI possui um aspecto mais abrangente. Neste trabalho os termos serão intercambiáveis, ou seja, serão equiparados, uma vez que o foco de atenção é avaliar o alinhamento estratégico de TI e Negócios com base no modelo apresentado e seus elementos de alinhamento.

\subsection{Estratégia Corporativa \& Tecnologia da Informa- ção para a competição}

Segundo Andrews (1971), Estratégia Corporativa é o caminho das decisões em uma companhia que determina e revela seus objetivos, propósitos, ou metas, produzindo as principais políticas e planos para atingir determinadas metas, bem como, define o nicho de negócio que a companhia deve focar, o tipo de organização econômica e humana que é ou pretende ser, e a natureza da contribuição econômica e não econômica que pretende dar a seus acionistas, empregados, clientes e comunidade. Cada vez mais, os gestores visualizam a TI como uma ferramenta imprescindível na obtenção da vantagem competitiva para seus negócios. No entanto uma pergunta que deve ser feita é em que situação a TI é realmente um diferencial para obter vantagem competitiva. Segundo Carr (2003), o que torna um recurso realmente estratégico, ou seja, que o habilite a servir de base para uma vantagem competitiva sustentada não é a sua disponibilidade, mas sua escassez. Complementa ainda, dizendo que só se ganha vantagem competitiva sobre os rivais aqueles que têm ou fazem algo que os outros não têm ou não fazem. Carr (2003) faz uma importante distinção entre tecnologias proprietárias e tecnologia infraestrutural. Uma tecnologia proprietária pode pertencer, de fato, ou na prática, a uma única empresa. A tecnologia proprietária pode ser a base de vantagens estratégicas de longo prazo, permitindo à empresa obter lucros superiores aos de rivais. Tecnologias infraestruturais geram muito mais valor quando compartilhadas do que quando usadas exclusivamente.

\subsection{Alinhamento estratégico}

$\mathrm{O}$ alinhamento estratégico integrado entre as áreas de negócio e de TI tem se tornado uma exigência nas organizações que visualizam manterem-se e crescerem sustentavelmente em um ambiente competitivo. Segundo Audy e Brodbeck (2003), essa integração chamada de alinhamento estratégico entre as funções de TI e os objetivos organizacionais tem sido apontada como um 
dos principais fatores de retorno do investimento e de agregação de valor ao negócio. Audy e Brodbeck (2003) também citam alguns dos conceitos mais significativos encontrados na literatura referentes ao alinhamento estratégico entre planejamento estratégico de negócios e planejamento estratégico de tecnologia de informação (PEN e PETI): - O primeiro conceito define que, quando o conjunto de estratégias de SI é derivado do conjunto estratégico organizacional, o alinhamento ou coordenação entre PEN e PETI é alcançado; - O segundo conceito estabelece que o elo entre PEN e PETI equivale ao grau no qual a missão, os objetivos e os planos de TI refletem e são suportados pela missão, pelos objetivos e pelos planos de negócio; - O terceiro conceito consiste que, para que sejam desenvolvidas, as competências e maximizadas as performances organizacionais, é necessário que o alinhamento estratégico entre PEN e PETI corresponda à adequação estratégica e à integração funcional entre os ambientes externo e interno. $\mathrm{O}$ ambiente externo é composto pelos mercados e o ambiente interno pela estrutura administrativa e recursos financeiros, tecnológicos e humanos; - O quarto conceito define que o alinhamento entre PEN e PETI está adequado entre a orientação estratégica do negócio e a orientação estratégica de TI.

\subsection{Modelo conceitual de alinhamento estratégico}

Existem vários modelos que têm o objetivo de alcançar o alinhamento estratégico de TI com o alinhamento estratégico do Negócio. Dos diversos modelos existentes, Audy e Brodbeck (2003) comentam modelos de Reich (1992) e Henderson e Venkatraman (1993). O modelo de Henderson e Venkatraman (1993) em conjunto com o modelo de Brodbeck (2001) serviram de base para o desenvolvimento deste trabalho, que se limitou a aprofundar-se nesses autores. O modelo de Henderson e Venkatraman (1993) preocupou-se em formalizar os componentes estratégicos, tanto do negócio como da TI, assegurando a similaridade dos processos. Dessa forma, foi possível demonstrar que os processos podem evoluir em paralelo ou sustentar um ao outro em determinados momentos. O modelo adotado por Henderson e Venkatraman (1993) mostra sua multidimensionalidade, nos caminhos de integração que estão representados em mão dupla, bem como no fluxo contínuo dos processos. Essa multidimensão pode ser comparada com os modelos de integração entre negócio e TI de King (1978), e aos fundamentos conceituais de planejamento e formulação es- tratégica de Mintzberg e Quinn (2001), onde os processos contínuos de revisão são considerados como elementos de aprendizagem organizacional. Segundo Audy e Brodbeck (2003), esse modelo considera o nível mais alto, que envolve o escopo, competência e redirecionamento do negócio (elementos do ambiente externo da organização), e o nível mais operacional da formulação estratégica (ambiente e o suporte interno às estratégias estabelecidas no nível mais alto), além das duas áreas de planejamento. Esse modelo possui um diferencial em relação aos demais, pois ele acrescenta duas variáveis de alinhamento: a adequação estratégica e a integração funcional. Os resultados da pesquisa de Henderson e Venkatraman (1993) levaram à definição de quatro perspectivas dominantes de ocorrência do alinhamento estratégico, as quais são obtidas a partir da combinação das ações nos seguintes domínios: 1- Execução Estratégica, onde a estratégia de negócios é articulada e é o caminho definidor da infraestrutura organizacional, que, consequentemente, define os requisitos da infraestrutura da TI; 2- Transformação Tecnológica, esta perspectiva de alinhamento envolve a avaliação de implementar a estratégia de negócio escolhida por meio da estratégia de TI apropriada, e a articulação da infraestrutura de TI elaborada a partir desses requerimentos; 3- Potencial Competitivo, esta perspectiva de alinhamento está interessada com a exploração das capacidades emergentes de IT para impactar novos produtos e serviços (escopo empresarial), influenciar os atributos fundamentais de estratégia (competências distintivas), e desenvolver novas formas de relacionamento. Ou seja, onde as escolhas estratégicas da TI definem a estratégia de negócios e em consequência sua infraestrutura; 4- Nível de Serviço, em que o alinhamento estratégico resulta da qualidade e quantidade de serviços de TI prestados à organização.

\subsubsection{Elementos de alinhamento estratégico}

Segundo Audy e Brodbeck (2003), existem vários elementos com os quais se podem obter uma promoção mais intensa de alinhamento durante o processo de planejamento estratégico. Os autores efetuaram vários estudos agrupando quatro grandes elementos, com determinado conjunto de variáveis promotoras de alinhamento, conforme apresentado abaixo em mais detalhes: O primeiro elemento de alinhamento, chamado de contexto organizacional, contém variáveis ligadas ao ambiente e à cultura organizacionais. Essas variáveis 
possibilitam verificar os ambientes internos e externos da empresa, quando se refere a porte, mercado, cultura, estrutura funcional do negócio e da TI, investimentos em negócio e TI e princípios gerais de gestão, incluindo planejamento. Essas variáveis são elementos importantes para a maior ou menor promoção do alinhamento pelas organizações. O segundo elemento foi chamado de modelo de planejamento estratégico, e incorporou variáveis sobre a estrutura de definição dos itens nos planos e etapas utilizados para o processo de planejamento. Os elementos desse modelo devem possibilitar a identificação dos componentes genéricos que compõem a estrutura dos planos de negócio e de TI. A missão, os objetivos, as estratégias de ação, os critérios de avaliação, as metas, os FCSs e os planos de ação são considerados elementos fundamentais para constar na estrutura do PEN. Já a infraestrutura de suporte de hardware, software e comunicação, adequação e integração dos processos e pessoas pelo SII, e consistência informacional entre as necessidades dos usuários e as informações fornecidas pelo SII, são elementos consideráveis para o PETI. A etapa de formulação de missão, estratégias, objetivos, metas, critérios, etc., e a etapa de implementação dos objetivos e projetos expressos nos planos de ação de negócio e de TI, determinam o processo de planejamento. O terceiro elemento compreende variáveis promotoras de alinhamento na etapa de formulação do processo de planejamento. Esse elemento encontra-se subdividido em dois outros elementos, sendo que um refere-se à adequação das estratégias de negócios e de TI e o outro à integração funcional entre as pessoas, infraestrutura e processos. Durante a etapa de formulação do processo de planejamento estratégico, as variáveis de verificação da promoção do alinhamento possibilitam a verificação do elo entre os itens especificados nos planos de negócio e de TI, bem como a consistência entre os objetivos de negócio e de TI. Na verificação dos estágios de promoção do alinhamento, é possível verificar a importância dessas variáveis para o modelo proposto, bem como dos pontos fortes e fracos, promotores de alinhamento durante esta etapa do processo. O quarto elemento compreende várias promotoras de alinhamento na etapa de implementação do processo de planejamento, e está subdividido em quatro elementos, a saber: a) metodologia de implementação do plano estratégico, onde é possível medi-la pela relação de itens ou atividades a serem implementadas, harmonização dos recur- sos, presença e agendamento de reuniões de revisão e ajuste, participantes e documentação das revisões; b) comprometimento, que é medido pelo cumprimento das metas determinadas, pelos participantes do planejamento e da implementação, pela comunicação entre os participantes, pelo patrocinador dos projetos de TI e pela dificuldade de implementação dos itens planejados; c) recursos despendidos, medidos por instrumentação, sincronização e grau de atendimento dos itens planejados; d) processos, medidos pela melhoria dos processos e pela identificação de novos projetos estratégicos. Segundo Audy e Brodbeck (2003), durante a etapa de implementação do processo de planejamento estratégico, as variáveis de verificação da promoção do alinhamento possibilitam verificar o método utilizado para a implementação das estratégias e objetivos definidos na etapa anterior, havendo também a harmonização dos recursos, o comprometimento das pessoas da empresa e a melhoria dos processos.

\section{Metodologia}

O emprego da metodologia de pesquisa possibilita a formulação e o planejamento de um conjunto de etapas, com o objetivo de levantar as informações necessárias, catalogá-las e analisá-las. Gil (1996) define pesquisa como sendo o processo racional e sistemático que objetiva proporcionar respostas, quando não se dispõe de informação suficiente para responder aos problemas propostos. Quanto aos objetivos desta pesquisa, a proposta de trabalho é classificada como uma pesquisa descritiva, considerando-se um estudo de caso na empresa Alfa com abordagem de análise quantitativa. O estudo de caso é uma forma de se fazer pesquisa social empírica ao investigar-se um fenômeno atual dentro de seu contexto de vida real, no qual as fronteiras entre o fenômeno e o contexto não são claramente definidas e na situação em que múltiplas fontes de evidência são usadas (YIN, 2001).

A análise quantitativa foi feita a partir da mensuração e tabulação das percepções dos profissionais de TI e de NE. De forma complementar, foram feitas entrevistas não estruturadas. O levantamento de percepções dos executivos de TI e do NE, a respeito do alinhamento estratégico da TI, teve como principal ferramenta um questionário estruturado. Este questionário foi composto de 47 questões, em escala do tipo Likert de 5 graus, 
de modo a obter do respondente sua percepção sobre variáveis que traduzissem o grau de alinhamento estratégico. Dos 8 questionários enviados (4 colaboradores de TI para o segmento distribuição de peças de reposição e 4 colaboradores do NE para o segmento de peças de reposição), todos foram preenchidos. $\mathrm{O}$ estudo considerou todas as pessoas de TI que trabalham no negócio de distribuição de peças de reposição (quatro), bem como os quatro principais colaboradores do NE para o segmento de distribuição de peças de reposição. Cem por cento dos colaboradores de TI foram envolvidos no estudo, bem como os principais executivos envolvidos no negócio. Visando assegurar a consistência dos resultados, foram levantados dados de várias fontes por diferentes meios: investigação documental e levantamento de percepções. A pesquisa documental baseou-se em documentos disponibilizados pela empresa Alfa, pertinente ao planejamento estratégico e o plano de negócio para o segmento de distribuição de peças de reposição. Para verificar o nível de alinhamento estratégico, foram utilizados como base os modelos de Henderson e Venkatraman (1993) e Audy e Brodbeck (2003), ou seja: para a etapa de Formulação do Planejamento Estratégico foi utilizado o método de Henderson e Venkatraman (1993) e Audy e Brodbeck (2003); Para a etapa de Implementação do Planejamento Estratégico, foi utilizado o método de Audy e Brodbeck (2003).

Procura-se responder ao seguinte problema de pesquisa: o planejamento estratégico de TI está realmente alinhado ao planejamento estratégico do negócio para o segmento de Distribuição de Peças de Reposição na empresa Alfa? Visando buscar respostas às perguntas de pesquisa formuladas no presente trabalho, o estudo é orientado a responder aos seguintes questionamentos: 1 . A estratégia de TI é alinhada à estratégia de negócios para o segmento de distribuição de peças de reposição da empresa Alfa? 2. As ações de TI na empresa Alfa promovem de forma contínua o alinhamento estratégico? 3. Quais são os pontos facilitadores e dificultadores do alinhamento estratégico de TI para o segmento de distribuição de peças de reposição da empresa Alfa?

\section{Apresentação e análise dos resultados}

\subsection{Caracterização do setor agrícola e da empresa estudada}

O setor agrícola possui grande importância no
Brasil. Nesse setor encontra-se o setor de máquinas agrícolas automotrizes como uma área de grandes oportunidades. A indústria de autopeças encontra-se em pleno desenvolvimento, com parte de suas vendas destinadas às montadoras, para exportação, para o mercado de reposição e o restante intrassetorial. A frota de máquinas agrícolas no País vem crescendo, conforme Anfavea (2013) o volume de venda de máquinas agrícolas automotrizes no ano de 2007 foi de 38.337 unidades, já no ano de 2012 o volume de vendas de máquinas agrícolas automotrizes foi de 70.139 unidades, ou seja, um aumento na venda anual de $82,9 \%$. Para acompanhar esse crescimento, as montadoras mantêm um número significativo de concessionárias para a venda de máquinas no varejo, bem como assistência técnica a esta frota circulante o que demandará naturalmente peças de reposição. Um aspecto muito interessante das concessionárias é o percentual de participação nos resultados a partir das vendas de peças de reposição; cada vez mais este segmento vem gerando resultados positivos. Naturalmente, as concessionárias agora visualizam o negócio de peças de reposição não apenas um complemento da venda da máquina, mas sim um negócio altamente lucrativo e com grandes oportunidades de desenvolvimento.

\subsection{Elemento de alinhamento estratégico para a eta- pa de formulação do planejamento estratégico}

Considerando-se que o alinhamento poderia ocorrer em uma escala de maior ou menor intensidade, podendo variar de um alinhamento total, parcial ou um alinhamento nulo, foi considerada a seguinte relação com as frequências observadas: "alto alinhamento", "alinhamento parcial" e "baixo alinhamento". Considerou-se para análise do alinhamento da etapa de formulação do planejamento estratégico, os modelos de Henderson e Venkatraman (1993) e Audy e Brodbeck (2003). Nos quadros 1,2 e 3 a seguir, é apresentada a relação dos níveis de promoção de alinhamento (Alto) e fracos (Parcial e Baixo) encontrados na empresa Alfa durante a etapa de formulação do planejamento. Conforme o Quadro 1, verifica-se que o alinhamento dentro da empresa Alfa para os profissionais de TI é considerado como um alinhamento Parcial (42\% de frequência), no que diz respeito aos profissionais do Negócio (NE) o alinhamento é considerado Baixo (75\% de frequência). De um modo geral, a intensidade de alinhamento é Baixo (58\% de frequência). 
Quadro 1 - Nível de alinhamento segundo as 4 perspectivas dominantes de ocorrência do alinhamento estratégico (Modelo de Henderson e Venkatraman - 1993)

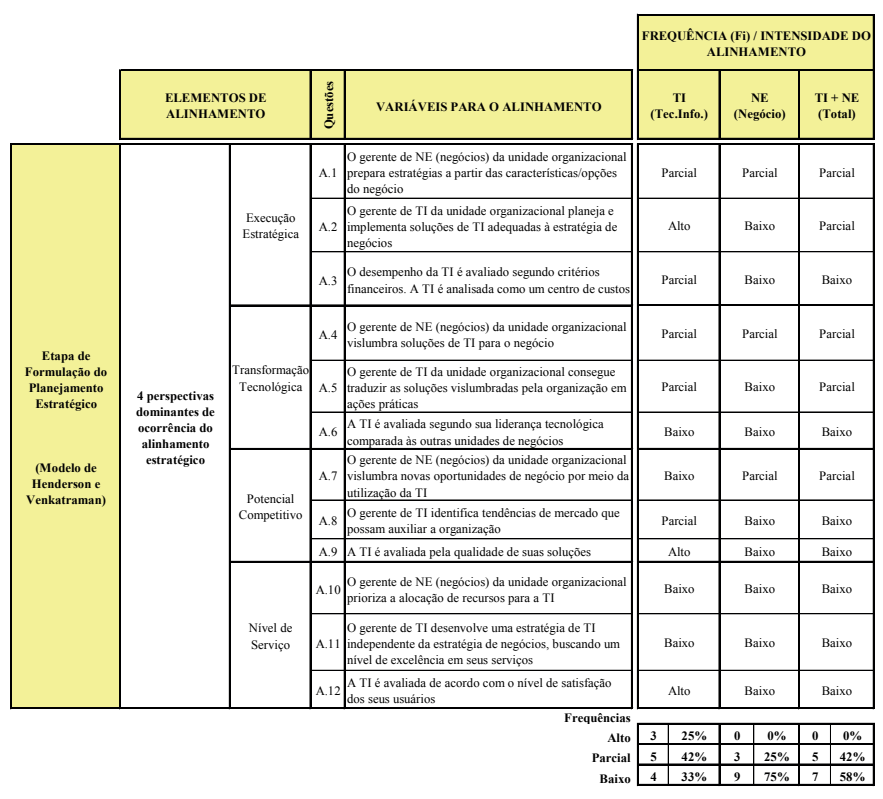

Fonte: Os autores, 2009

Analisando cada perspectiva separadamente, temos a "Execução Estratégica" em que a estratégia de negócios é articulada e é o caminho definidor da infraestrutura organizacional, que, consequentemente, define os requisitos da infraestrutura da TI considera um alinhamento Parcial de uma forma geral. No entanto, quando se analisa o alinhamento aberto em TI e NE, verifica-se para TI um alinhamento Parcial versus Baixo alinhamento para o Negócio. Essa situação de apresentar um alinhamento contraditório entre TI e NE é compreensível quando das entrevistas não estruturadas com os executivos envolvidos. Na questão A.2 "O gerente de TI da unidade organizacional planeja e implementa soluções de TI adequadas à estratégia de negócios" é apresentado alto alinhamento para TI e baixo alinhamento para NE, isso ocorre, pois, na visão do Gerente de TI, toda e qualquer melhoria ou solicitação de implementação é considerada como adequada à estratégia do negócio. A realidade demonstra que não existem reuniões semanais, quinzenais, mensais ou anuais para entender quais as estratégias do negócio. Conclui-se, para essa perspectiva, que os gerentes de TI não estão em sintonia com gerentes de negócio. A perspectiva "Transformação Tecnológica" apresenta uma intensidade de alinhamento parcial nas variáveis para o alinhamento. Essa perspectiva envolve a avaliação de implementar a estratégia de negócio escolhida por meio da estratégia de TI apropriada, e a articulação da infraestrutura de TI elaborada a partir desses requerimentos. A perspectiva "Potencial Competitivo" apresenta uma intensidade de alinhamento baixa nas variáveis para o alinhamento. Essa perspectiva está interessada com a exploração das capacidades emergentes de TI para impactar novos produtos e serviços (escopo empresarial), influenciar os atributos fundamentais de estratégia (competências distintivas), e desenvolver novas formas de relacionamento, ou seja, onde as escolhas estratégicas da TI definem a estratégia de negócios e em consequência sua infraestrutura; A perspectiva "Nível de Serviço" apresenta as variáveis para o alinhamento com a menor intensidade, 100\% de frequência para o baixo alinhamento. Esse alinhamento estratégico resulta da qualidade e quantidade de serviços de TI prestados à organização. O grau de alinhamento baixo obtido para esta perspectiva é mais acentuado para os executivos do NE em que apresenta $100 \%$ de variáveis com alinhamento baixo. As variáveis respondidas por executivos de TI também figuram com um alinhamento baixo na ordem de 67\% de frequência. Esse alinhamento baixo condiz com a realidade vivenciada na empresa Alfa, pois o nível de pendências por parte de TI é muito grande e a demora na conclusão das mesmas é longa. Isso se deve, muitas vezes, pela indisponibilidade de alocação de recursos para TI. Conforme Quadro 2, a presença da promoção do alinhamento durante a etapa de formulação do processo de Planejamento Estratégico (Adequação Estratégica) foi Baixa em 7 das 11 variáveis, atingindo 64\%. Para 4 variáveis, ou $36 \%$, a presença da promoção do alinhamento se mostrou parcial e nenhum item com alinhamento alto. O grau de alinhamento baixo obtido com uma frequência de 7 variáveis apresenta um ponto interessante, verificando-se as respostas do ponto de vista do NE, o alinhamento é baixo com $73 \%$ de frequência. Por outro lado, analisando-se, do ponto de vista de TI, o alinhamento é parcial com $45 \%$ de frequência. Conforme a análise documental e entrevista não estruturada, a empresa Alfa não possuía um plano estratégico de TI formalizada. Na visão determinada pelo NE, não se faz referências claras a iniciativas de TI, levando a crer em um alinhamento de nível baixo. Esse fato é comprovado conforme apresentado na percepção dos entrevistados (questão B1 a B11). 
Quadro 2 - Nível de alinhamento para o elemento Adequação Estratégica (Modelo de Audy e Brodbeck - 2003)



Fonte: Os autores, 2009

Conforme Quadro 3, a presença da promoção do alinhamento, durante a etapa de formulação do processo de Planejamento Estratégico (Consistência entre objetivos de negócios e de TI), foi parcial em 5 variáveis, atingindo $63 \%$. Para 3 variáveis, ou $38 \%$, a presença da promoção do alinhamento se mostrou baixa e nenhum item com alinhamento alto. O grau de alinhamento parcial obtido com uma frequência de 5 variáveis das 8 totais, também apresenta um ponto interessante, verificando as respostas do ponto de vista do negócio, o alinhamento é parcial e baixo com uma frequência de $50 \%$ para ambos os casos. Por outro lado, analisando-se, do ponto de vista de TI, o alinhamento é considerado alto com $88 \%$ de frequência das variáveis.

Quadro 3 - Nível de alinhamento para o elemento Consistência entre objetivos de negócios e de TI (Modelo de Audy e Brodbeck - 2003)

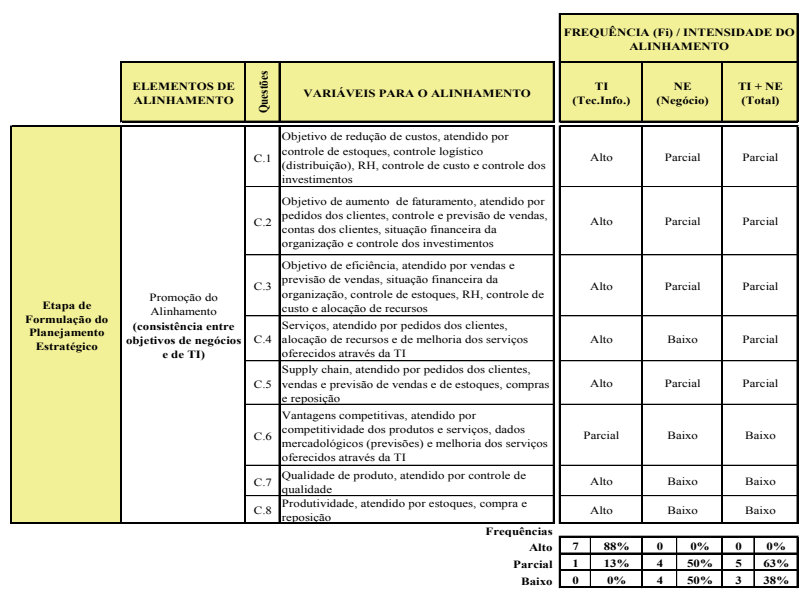

Fonte: os autores, 2009.

\subsection{Elemento de alinhamento estratégico para a etapa de implementação do Planejamento Es- tratégico}

Conforme Quadro 4, na etapa de implementação do planejamento estratégico, os indicadores relacionados aos elementos de alinhamento: metodologia, gerenciamento, comprometimento e processos, apresentam um grau de promoção de alinhamento baixo, considerando-se uma frequência de 10 das 16 variáveis na empresa Alfa, ou seja, $63 \%$. Para NE, verifica-se uma intensidade baixa de alinhamento (69\%) e para TI é apresentado um alinhamento Alto (50\%).

Quando se analisa cada elemento separadamente, notam-se alguns pontos interessantes: $\underline{\text { metodologia - as }}$ variáveis para esse elemento indicaram um alinhamento baixo com $57 \%$ de frequência para suas variáveis. O envolvimento dos gerentes da organização nas decisões apontou um grau de alinhamento Parcial, por outro lado, apontou que TI não identifica proativamente projetos de suporte aos objetivos estratégicos e que TI não está de acordo com as expectativas da organização. A questão D.7 remete que TI implementa práticas recomendadas por consultoria especializada. Esta apresenta um alinhamento baixo, pois a frequência das respostas provenientes do pessoal de negócio é que isso não está sendo refletido satisfatoriamente ao negócio. Gerenciamento (monitoramento e coordenação): as variáveis para esse elemento indicam um alinhamento parcial. Apesar de existir diversos indicadores de acompanhamento da qualidade do serviço e o desempenho de alguns equipamentos (servidores e rede), não existiam indicadores que avaliassem a eficácia das ações implementadas no negócio. Isso se torna claro com a frequência de $67 \%$ nas respostas dos gestores da área de NE. Comprometimento: as variáveis para este elemento indicam um alinhamento baixo de 100\% de frequência nas variáveis para alinhamento. A principal observação referente a esse elemento de alinhamento é que os gerentes da organização não estão comprometidos em auxiliar a TI na implantação de suas ações, conforme questionário respondido (F3) onde apresenta um alinhamento baixo. Processos: as variáveis para este elemento indicam um alinhamento baixo de 100\% de frequência nas variáveis para alinhamento. A principal observação referente a esse elemento de alinhamento é que a organização de TI não monitora as necessidades internas do negócio e as capacidades de TI para atender estas necessidades, a TI da empresa Alfa espera o negócio solicitar 
sua necessidade operacional para então entrar em ação. Com isso, sem a identificação de oportunidades por parte de TI, o resultado obtido em particular dos executivos de negócio é um alinhamento baixo.

Quadro 4 - Nível de alinhamento para os elementos de metodologia, gerenciamento, comprometimento e processos (Modelo de Audy e Brodbeck - 2003)

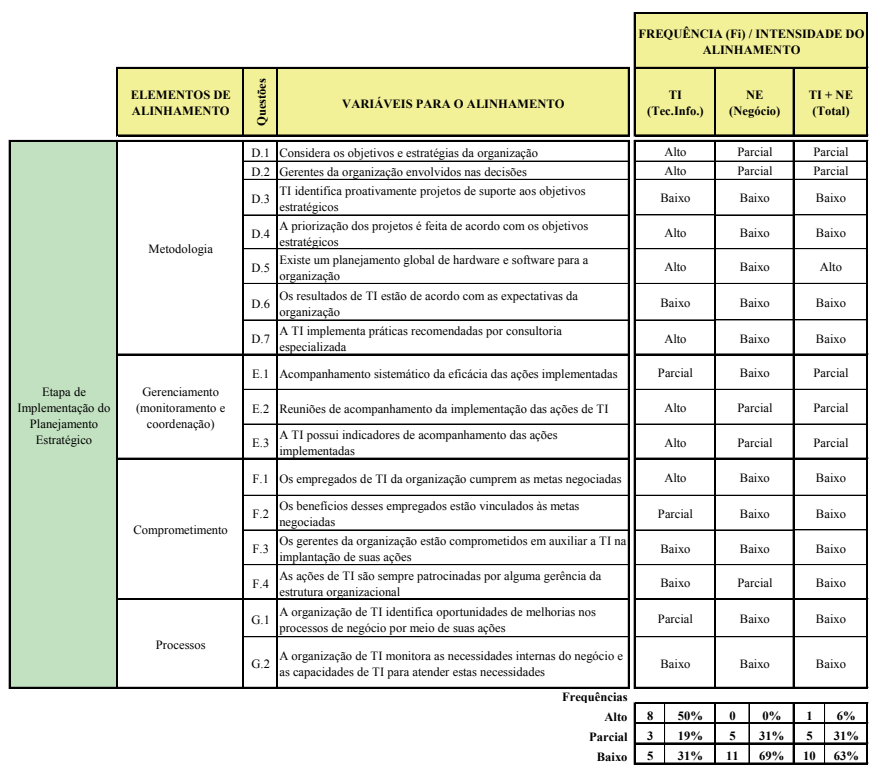

Fonte: Os autores, 2009

É importante mencionar que quando verificados os gráficos da percepção dos executivos de TI e da percepção dos executivos de NE (negócio), para os executivos de negócio as variáveis para o alinhamento ficaram todas com uma intensidade do alinhamento baixo. Por outro lado, na percepção dos executivos de TI, esse alinhamento ficou em sua maioria no nível parcial e alto. Após a apresentação dos dados, foi possível responder as questões de pesquisa efetuadas.

Os resultados do estudo de caso apontaram que, o contexto organizacional na empresa Alfa indicava condições desfavoráveis à promoção de alinhamento estratégico de TI, ou seja, não existia satisfação dos gerentes com a informação disponibilizada, não havia a proximidade física entre gerentes de TI e de negócio e usuários (colaboradores localizados em diferentes Estados do Brasil), enfim tudo levava a crer em um desalinhamento entre TI e o negócio. Ficou ainda mais claro o desalinhamento quando da interpretação da percepção dos executivos de TI e de negócio. Conforme foi mencionado anteriormente na apresentação dos resultados, a estratégia de TI não é formalmente definido, o nível de serviço é insatisfatória, a importância dada a TI pelo gerenciamento do topo é baixa, TI não identifica proativamente projetos de suporte aos objetivos estratégicos, as recomendações de consultorias não geram o resultado esperado no negócio, não existem medidores para avaliar a efetividade das ações de TI no negócio, os gerentes da organização não estão comprometidos em auxiliar a TI na implantação de suas ações, ou seja, todos esses pontos deficitários levam a um alinhamento de nível baixo. Em função dos baixos níveis de, falta de comprometimento por parte do negócio, falta de proatividade de TI, pode-se considerar que TI na empresa Alfa não promove o alinhamento estratégico nos dias atuais e não promove o alinhamento estratégico de uma forma sustentável.

$\mathrm{Na}$ questão dos pontos facilitadores, pode-se observar que houve envolvimento dos Gerentes da organização, bem como existe um planejamento global de hardware e software para a organização. Contudo, em relação aos dificultadores, a estratégia de TI não é formalmente definida, há inconsistência entre objetivos do negócio e de TI, o nível de serviço por parte de TI é insatisfatório, a importância dada a TI pelo gerenciamento do topo é baixa, a TI não identifica proativamente projetos de suporte aos objetivos estratégicos, as recomendações de consultorias não geram o resultado esperado no negócio, não existem medidores para avaliar a efetividade das ações de TI dentro do negócio, os gerentes da organização não estão comprometidos em auxiliar a TI na implantação de suas ações.

\section{Considerações finais e recomendações}

O alinhamento estratégico entre TI e negócio pode realmente trazer melhorias nos processos internos e externos, bem como vantagens competitivas sustentáveis, porém é necessário que exista efetivamente este alinhamento. Considera-se que essa pesquisa atingiu em grande parte seu objetivo ao identificar como garantir que a estratégia de TI estivesse alinhada às estratégias do negócio para o segmento de distribuição de peças de reposição da empresa Alfa, de maneira a contribuir para a obtenção de uma melhora efetiva em seus processos internos e externos, bem como uma real vantagem competitiva. Os resultados encontrados na empresa Alfa demonstram claras oportunidades de melhoria para elevar o nível de alinhamento. Como sugestão, seria interessante definir um plano de ação para cada ponto deficitário encontrado 
na tentativa de se alinhar ao máximo. Entre as ações mais importantes, é importante conscientizar os gerentes da organização da importância em auxiliar a TI na implantação de suas ações, reunião mensal em que gerentes de TI tragam toda melhoria ou implementação solicitada para em conjunto com NE criticar quais melhorias ou implementações de soluções de TI estão adequadas à estratégia do negócio, implantação de indicadores de desempenho, pois seguramente isso trará uma melhora efetiva em seus processos internos e externos, bem como uma real vantagem competitiva.

\section{Referências}

ANDREWS, K. R. The concept of corporate strategy. Homewood-USA: Dow Jones - Irwin, 1971.

ANFAVEA Anuário da indústria automobilística brasileira. Disponível em: <http://www.anfavea.com.br/anuario. html>. Acesso em: 15 jul. 2013.

AUDY J. L. N; BRODBECK A. F. Sistemas de informação, planejamento e alinhamento estratégico nas organizações. Porto Alegre: Bookman, 2003.

BRODBECK, A. F. Alinhamento estratégico entre os planos de negócio e de tecnologia de informação: um modelo operacional para a implementação. 2001. 332 f. Tese (Doutorado em Administração) - Universidade Federal do Rio Grande do Sul, Porto Alegre, 2001.
CARR, N. G. TI já não importa. Harvard Business Review - Brasil, São Paulo, 2003.

GIL, A. C. Como elaborar projetos de pesquisa. São Paulo: Atlas, 1996.

HENDERSON, J. C.; VENKATRAMAN, N. Strategic alignment: leveraging information technology for transforming organizations. IBM Systems Journal, New York, v. 32, n. 1, p. 4-16, 1993.

KING, W.R. Strategic planning for management information systems. MIS Quarterly, Minnesota, v. n. p. 27-37, 1978.

LEDERER, A. L.; SETHI, V. Key prescriptions for strategic IS planning. Journal of Management Information Systems, USA, v. 13, n. 1, p. 35-62, Summer 1996.

MINTZBERG, H.; QUINN, J. B. O processo de estratégia. Porto Alegre: Bookman, 2001.

REICH, B. H. Investigating the linkage between business objectives and information technology objectives: a multiple case study in the insurance industry. Columbia: Unpublished dissertation, University of British Columbia, 1992.

REICH, B. H.; BENBASAT, I. Measuring the linkage between business and information technology objectives. MIS Quarterly, USA, v. 20, n. 1, p. 55-81, Mar. 1996.

YIN, R. K. Estudo de caso: planejamento e métodos. 2 ed. Porto Alegre: Bookman, 2001. 